\title{
Back pain and collapse associated with receding subarachnoid blockade
}

\author{
Margaret M. Coleman FFARSCI, \\ Arun Bardwaj FFARCSI, \\ Vincent V.W.S. Chan MD FRCPC
}

Purpose: Back pain and sudden loss of consciousness during recovery from spinal anesthesia are rare. Severe pain may raise fears of serious neurological damage and result in inappropriate management. Bladder distention may present in this way and clinicians should be alert to this possibility and communicate this to nursing staff.

Clinical features: A lumbar spinal anesthetic was performed during a volunteer study, using $15 \mathrm{mg}$ hyperbaric bupivacaine in a healthy 31 yr old man. During recovery, five hours later, as the block regressed to the $L_{1-2}$ level, he complained of acute, severe back pain and briefly lost consciousness secondary to profound bradycardia. Bladder cathetherization yielded $900 \mathrm{~mL}$ urine with immediate and complete relief of symptoms.

Conclusion: Severe pain secondary to bladder overdistention in the presence of neuroaxial blockade may be referred to the thoracolumbar area, mediated by intact sympathetic afferents. As the saccral parasympathetic supply remains paralyzed, there is no subjective sensation of bladder stretching. If untreated, bladder distention can lead to excessive supraspinal parasympathetic outflow resulting in vasovagal syncope.

Objectif : Les douleurs dorsales et la perte de conscience soudaine pendant la récupération de la rachianesthésie sont rares. Les douleurs intenses font craindre des lésions neurologiques sévères et peuvent entrainer une attitude thérapeutique inappropriée. La distension vésicale peut alors se présenter et les cliniciens doivent penser à cette éventualité et en avertir le personnel infirmier.

Eléments cliniques : Une rachianesthésie lombaire a été réalisée pendant une étude auprès de volontaires, en utilisant $15 \mathrm{mg}$ de bupivacaïne hyperbare chez un homme en santé de 31 ans. Pendant la récupération, cinq heures plus tard, au moment où le blocage neuromusculaire régressait au niveau de $\mathrm{L}_{\mid \cdot 2}$, il s'est plaint de douleurs dorsales aiguës et sévères et a subi une brève perte de conscience secondaire à une bradycardie profonde. Le cathétérisme vésical a fourni $900 \mathrm{~mL}$ d'urine et un soulagement immédiat et complet des symptômes.

Conclusion : Des douleurs sévères, secondaires à une surdistension vésicale lors d'un blocage neuraxial, peut irradier dans la région thoracolombaire par la médiation de fibres sympahtiques afférentes intactes. Comme l'innervation parasympathique sacrée demeure paralysée, il n'y a pas de sensation subjective de gonflement vésical. Non traitée, la distension vésicale peut provoquer une décharge parasympathique supraspinale excessive à l'origine d'une syncope vaso-vagale.

From the University of Toronto, Department of Anesthesia, The Toronto Hospital, Western Division, 399 Bathurst Street, Toronto, Ontario, M5T 2S8, Canada.

Address correspondence to: Dr. Margaret Coleman, Phone: 416-603-5118; Fax: 416-603-6494; E-mail: margaretcoleman@sprint.ca Accepted for Publication February 18,1999 
$\mathrm{T}$ HE incidence of back pain after spinal anesthesia is low in hospitalized patients but there is a $30-50 \%$ incidence of mild backache in outpatients. ${ }^{1}$ It is very unusual to see severe back pain during the resolution phase of spinal anesthesia. Mild backache may be a result of ligamentous injury, reflex muscle spasm, profound relaxation of the spinal musculature and patient positioning e.g., in the lithotomy position. If pain is severe, major neurological injury must be ruled out. Possible causes include epidural or spinal hematoma, direct trauma to nerves or the spinal cord, epidural abscess, unsuspected malignant disease of the spine or adhesive arachnoiditis. Syncope during spinal anesthesia may be associated with cardiac arrest if the cardioacceleratory fibres are affected in a high block or it may be secondary to a sudden and profound loss of venous return with a greatly reduced cardiac output. We present a case of severe back pain and syncope in a conscious patient during recovery from subarachnoid blockade.

\section{Case Report}

A 31 yr old healthy man, ASA 1, underwent spinal anesthesia in a volunteer study to assess the minimally effective concentration of bupivacaine. Hyperbaric bupivacaine, $15 \mathrm{mg}$ was injected through a $25 \mathrm{G}$ Whitacre needle, inserted easily at the $\mathrm{L}_{3-4}$ interspace while the patient was lying decubitus. This resulted in a sensory block to $T_{12}$ and complete lower limb paralysis. The patient was hemodynamically stable throughout the procedure and received $500 \mathrm{ml}$ normal saline in total. However, during recovery, five hours later, he became acutely bradycardic (34-40 bpm) and transiently lost consciousness. He was placed in the Trendelenberg position, oxygen was administered and he regained consciousness promptly with spontaneous resolution of bradycardia. On awakening, he was in great distress, complaining of severe low back pain which radiated into the flanks. He was cold, clammy and diaphoretic, with a heart rate of 45$50 \mathrm{bpm}$ and blood pressure of $110 / 70 \mathrm{mmHg}$. Sensory blockade had now regressed to the anterior thigh $\left(\mathrm{L}_{1-2}\right)$, but lower limb blockade remained. Examination of the back revealed no tenderness, muscle spasm or bruising. Abdominal examination was very difficult owing to tensing of the abdominal musculature and the patient's unwillingness to lie still. Although he had no sensation of bladder distention, he was catheterized, because of a history of overflow incontinence during a previous spinal anesthetic. This yielded $900 \mathrm{~mL}$ urine with immediate and complete relief of his symptoms.

\section{Discussion}

This case illustrates several interesting points. Severe back pain secondary to bladder distention is unusual. Bladder discomfort and pain e.g., pain from a bladder stone is conveyed by both parasympathetic and sympathetic pathways. ${ }^{2}$ In this case the sympathetic visceral afferents (from $T_{10}-L_{2}$ ), which were functioning above the level of the block, were activated. This pain was referred to the back because the sympathetic fibres share the same population of dorsal horn neurons in the spinal cord as the somatic afferents which arise from the thoracolumbar musculature. Hence, visceral pain from bladder overdistention can be perceived as somatic pain from the thoraco-lumbar area. ${ }^{3}$ In this volunteer the parasympathetics of $S_{2-4}$ remained paralyzed, so the "classical" feeling of bladder fullness was not appreciated.

During bladder filling, increased tension stimulates stretch receptors in the bladder wall and afferent impulses pass along parasympathetic fibres in the pelvic nerves to the spinal cord. ${ }^{2}$ This results in detrusor contraction with subsequent voiding, ultimately controlled supraspinally by the micturition center, in neurologically intact individuals. In this man, pain impulses carried by sympathetic fibres reached the micturition center resulting in supraspinal stimulation of the parasympathetic system in an attempt to initiate voiding, via $S_{2.4}$ nerves which remained paralyzed. Consequently, only the parasympathetics above the level of the block were activated resulting in bradycardia, vasodilatation and syncope.

General anesthesia may also result in urinary retention but as the parasympathetic supply to the bladder is unaffected, the patient is aware of bladder distension despite an inability to void. A presentation of back pain would be unlikely as the patient would be catheterized and a vaso-vagal episode averted.

It is important to remember that autonomic nervous activity frequently returns only after the return of sensory and motor function. ${ }^{4}$ While day case patients are discharged only after they demonstrate an ability to void, in- patients are often allowed to return to the ward when they show partial regression of spinal blockade, such as the ability to elevate the legs. However, this only indicates recovery of somatic function and not necessarily reversal of autonomic function, so voiding may remain impossible for several hours as seen in this case.

Sudden onset, severe and persistent back pain after spinal anesthesia raises the concern of spinal hematoma, especially in the face of residual neurological deficit (despite partial regression). Other causes such as. direct trauma to the nerves or spinal cord, 
epidural abscess, unsuspected spinal malignant disease or adhesive arachnoiditis did not fit the time frame given in this case i.e. during the recovery phase of the anesthetic. This clinical scenario may mislead clinicians, resulting in panic, inappropriate intervention or expensive radiological or cardiac investigation.

This case is unusual in that severe back pain and syncope occurred in a conscious patient who was otherwise asymptomatic and exhibited no overt signs of urinary retention.

It would be inappropriate to suggest that all patients receiving $15 \mathrm{mg}$ bupivacaine, should be catheterized as there are associated risks of urinary tract infection and bacteremia. However, physicians should appreciate the importance of input/output measurements in all patients who have undergone subarachnoid blockade, irrespective of the surgery performed or hemodynamic stability. The urge to void disappears quickly after spinal injection of local anesthesia and bladder function remains impaired until the sensory block regresses to the $S_{3}$ segment. With the use of longer acting agents, the capacity of the bladder may be exceeded and retention may cause irreversible detrusor damage leading to incontinence and recurrent infections. ${ }^{5}$ In receding subarachnoid blockade the onset of sudden severe back pain should alert the anesthetist to the possibility of severe bladder distention. This is a problem which is easy to confirm and treat once suspected and may avoid unnecessary investigations and inappropriate management.

\section{References}

1 Flatten $H$, Raeder J. Spinal anaesthesia for outpatient surgery. Anaesthesia 1985; 40: 1108-11.

2 McMinn RMH. Last's Anatomy. Regional and Applied, 8th ed. Edinburgh: Churchill Livingstone, 1990: 384.

3 Covino BG, Scott DB, Lambert DH. Handbook of Spinal Anaesthesia and Analgesia. Philadelphia: W.B. Saunders, 1994: 57

4 Daos FG, Virtue RW. Sympathetic-block persistence after spinal or epidural analgesia. JAMA 1963; 183: 285-7.

5 Kamphuis ET, Ionescu TI, Kuipers PWG, de Gier J, van Venrooij GEPM, Boon TA. Recovery of storage and emptying functions of the urinary bladder after spinal anesthesia with lidocaine and with bupivacaine in men. Anesthesiology 1998; 88: 310-6. 